\title{
Hyperthermia Suppresses Post - In Vitro Proliferation and Tumor Growth in Murine Malignant Melanoma and Colon Carcinoma
}

\author{
THEODORA MANTSO ${ }^{1,2}$, STAVROS VASILEIADIS $^{3}$, EVANGELI LAMPRI $^{4}$, \\ SOTIRIS BOTAITIS ${ }^{5}$, SEBACHEDIN PERENTE ${ }^{5}$, CONSTANTINOS SIMOPOULOS ${ }^{6}$, \\ KATERINA CHLICHLIA ${ }^{7}$, AGLAIA PAPPA ${ }^{7}$ and MIHALIS I. PANAYIOTIDIS ${ }^{1,2}$ \\ ${ }^{1}$ Department of Applied Sciences, Northumbria University, Newcastle Upon Tyne, U.K.; \\ ${ }^{2}$ School of Life Sciences, Heriot Watt University, Edinburgh, U.K.; \\ ${ }^{3}$ Department of Obstetrics and Gynecology, Medical School, \\ Democritus University of Thrace, Alexandroupolis, Greece; \\ ${ }^{4}$ Department of Pathology, University of Ioannina, Ioannina, Greece; \\ ${ }^{5}$ First and ${ }^{6}$ Second Departments of Surgery, Medical School, \\ Democritus University of Thrace, Alexandroupolis, Greece; \\ ${ }^{7}$ Department of Molecular Biology and Genetics, Democritus University of Thrace, Alexandroupolis, Greece
}

\begin{abstract}
Background: Several studies have highlighted hyperthermia's ability to enhance the effectiveness of radiation and chemotherapy in various in vitro and in vivo cancer models. Materials and Methods: In vivo murine models of malignant melanoma and colon carcinoma were utilized for demonstrating hyperthermia's therapeutic effectiveness by examining levels of caspase 3, COX-2 and phospho-H2A.X (Ser139) as endpoints of apoptosis, proliferation and DNA damage respectively. Results: Hyperthermia induced in vitro cytotoxicity in malignant melanoma (B16-F10) and colon carcinoma (CT26) cell lines. In addition, it reduced post-in vitro proliferation and suppression of tumor growth by inducing the expression of caspase-3 and phospho-H2A.X (Ser139) while reducing the expression of COX-2 in both murine cancer models. Conclusion: Hyperthermia can exert therapeutic effectiveness against melanoma and colon carcinoma by inhibiting a number of critical cellular cascades including apoptosis, proliferation and DNA damage.
\end{abstract}

This article is freely accessible online.

Correspondence to: Prof. Mihalis I. Panayiotidis, Department of Applied Sciences, Group of Translational Biosciences, Faculty of Health \& Life Sciences, Northumbria University, Ellison Building A516, Newcastle Upon Tyne, NE1 8ST, U.K. Tel: +44 01912274503,e-mail: m.panagiotidis@northumbria.ac.uk

Key Words: Hyperthermia, malignant melanoma, colon carcinoma, experimental cancer therapeutics, proliferation, apoptosis, DNA damage.
One of the most aggressive and deadliest malignancies of all solid tumors is malignant melanoma (MM). Its incidence rates have been continuously rising worldwide while the disease accounts for the majority of skin cancer-related deaths (1-4). MM occurs from the accumulation of genetic and metabolic abnormalities of melanocytes as well as other contributing factors like numerous atypical nevi (i.e. benign proliferations of melanocytes), genetic predisposition and solar ultraviolet (UV) (5-7). In particular, evidence from various studies have linked exposure to UV radiation with the increased occurrence of the disease, due to the mutagenic properties of UVR, thus making it the leading risk factor (810). The majority of $\mathrm{MM}$ cases present an active $B R A F$ mutation, with $\mathrm{V}^{600 \mathrm{E}}$ being the most common one accounting for $90 \%$ of cases. The activation of other oncogene pathways including RAS, $c-K I T, N R A S, P I 3 K$ and $P T E N$ as well as inactivation of tumor suppressors such as $C D K N 2 A$ have been also associated with the development of the disease $(11,12)$. However, although there has been significant progress on understanding MM's biology, the disease's pathogenesis has yet to be well characterized. Although there is remarkable progress in developing more targeted therapeutic approaches there is still a great need to design more effective treatment strategies due to the poor responsiveness of MM to current therapeutic means (13-15).

On the other hand, colorectal or colon carcinoma (CRC) is a tumor type originating from epithelial cells residing in the colon or rectum of the gastrointestinal tract $(16,17)$. $\mathrm{CRC}$ is the third most common type of cancer diagnosed globally while it is the fourth leading cause of cancer-related 
deaths worldwide $(18,19)$. About $70 \%$ of the cases are caused by somatic mutations with familial and hereditary CRC representing $10-30 \%$ of these cases (20-22). Findings from various studies have revealed a number of molecular events responsible for the development of the disease including lack of genomic stability, chromosomal instability, defects in DNA repair pathways, epigenetically-induced gene silencing, mutation-induced inactivation and/or activation of tumor-suppressor genes and oncogenes respectively $(23,24)$. Undoubtedly, current therapeutic regimens including adjuvant treatment protocols, with chemotherapeutic drugs as well as monoclonal antibodies, have improved the overall CRC survival rates. However, due the disease's heterogeneity, many patients still do not respond to current treatments thus making the quest for more effective therapeutic options far more important (25-27).

Hyperthermia is the application of exogenous heat resulting in either direct or indirect killing of tumor cells when applied alone or in combination with other therapeutic means (e.g. radiation, chemotherapy, etc.) respectively. It represents the fourth most common cancer treatment modality following surgery, radiation and chemotherapy (28). Early studies have shown that hyperthermia, in combination with radiation therapy, exerts a potentiation effect of its therapeutic potential $(29,30)$. Since then, a number of studies have aimed to investigate hyperthermia's therapeutic potential on various cancer types (e.g. mammary and prostate carcinomas, osteosarcoma, glioma, melanoma, etc.) by utilizing a number of in vitro and in vivo models (31-35). Overall, hyperthermia it has been shown to exert a wide range of effects including i) direct cytotoxicity in tumor cells, ii) modifications in the tumor microenvironment, iii) induction of heat shock proteins, iv), alterations in the immune response, v) stimulation of necrotic and apoptotic cascades, vi) changes in cell cycle-related signaling pathways, vii) changes in blood flow, oxygen and nutrient delivery to the site of tumor and finally, viii) enhancement of therapeutic outcome when applied in combination with other regimens (36-38). To this end, a recent study from our group has demonstrated the application of hyperthermia in an in vitro model of human malignant melanoma resulting in apoptotic activation while enhancing the efficacy of both targeted and non-targeted therapeutic drugs (39). Hence, in this study, we have aimed to utilize post-in vitro murine models of malignant melanoma and colon carcinoma in order to validate hyperthermia's effectiveness as a monotherapy protocol.

\section{Materials and Methods}

Cell lines. The murine malignant melanoma (B16-F10) cell line was purchased from LGC Standards (Middlesex, UK). The murine colon carcinoma (CT26) cell line was a kind gift from Dr. Chlichlia (Department of Molecular Biology \& Genetics, Democritus University of Thrace). Both cell lines were maintained in Dulbeccos's
Modified Eagle Medium (DMEM), supplemented with $10 \%$ fetal bovine serum, $2 \mathrm{mM} \mathrm{L-glutamine}$ and $1 \%$ pen/strep $(100 \mathrm{U} / \mathrm{ml}$ penicillin, $100 \mu \mathrm{g} / \mathrm{ml}$ streptomycin). Cells were cultured in a humidified atmosphere at $37^{\circ} \mathrm{C}$ and $5 \% \mathrm{CO}_{2}$. They were grown as monolayer cultures and sub-cultured when reaching $80-90 \%$ confluence. Both cell lines were cultured for up to 15-20 passages before new vials were utilized. All cell culture media and reagents were purchased from Labtech International Ltd (East Sussex, UK) and cell culture plasticware were obtained from Corning (NY, USA).

Hyperthermia exposures. Cells were exposed to either $43^{\circ} \mathrm{C}$ or $45^{\circ} \mathrm{C}$ for various time periods in a standard $5 \% \mathrm{CO}_{2}$ incubator. Briefly, the appropriate number of cells was plated and incubated at $37^{\circ} \mathrm{C}$ overnight. On the following day, the medium was refreshed and cells were transferred into a $5 \% \mathrm{CO}_{2}$ incubator set at either of the hyperthermic temperatures before exposure to various time points. Then, cells were returned back to a $37^{\circ} \mathrm{C}$ incubator for additional incubation periods (post-exposure).

Cell viability assay. Cell viability levels were determined immediately after exposure, as well as at $24 \mathrm{~h}$ post-exposure, by utilizing the Alamar-blue assay. In brief, $10 \mu \mathrm{l}$ of resazurin sodium salt dissolved in PBS $(1 \mathrm{mg} / \mathrm{ml})$ was added into each well of $\alpha 96-$ well plate $(100 \mu \mathrm{l})$ and mixed by gentle shaking. The plates were incubated at $37^{\circ} \mathrm{C}$ for $2 \mathrm{~h}$ and then the samples were transferred into the wells of a black opaque plate. Fluorescence was monitored at $400 \mathrm{Exc} / 505 \mathrm{Emm}(\mathrm{nm})$ by using a SpectraMax M5 multimode plate reader (Molecular Devices, LLC, Sunnyvale, USA). Cell viability was expressed as percentage of control $\left(37^{\circ} \mathrm{C}\right)$ cells. Five replicates $(n=5)$ of each experimental condition were used under each experiment.

Animals. C57BL/6J mice were purchased from the Hellenic Pasteur Institute (Athens, Greece) and were raised at the Animal House Unit (Laboratory of Experimental Surgery, Democritus University of Thrace, Alexandroupolis, Greece). On the other hand, BALB/c mice were kindly provided by Dr Chlichlia (Department of Molecular Biology \& Genetics, Democritus University of Thrace, Greece) and were also maintained at the Animal House Unit of the same Institution. The mice were housed in sterile polycarbonate cages (maximum 5 mice per cage) at RT, on a 12 h light-12 h dark cycle, and were provided with tap water and commercial pelleted diet (Mucedola, Italy).

In vivo xenograft murine models of melanoma and colon carcinoma. A total of 30 female mice (8-12 weeks old, weighted 20-25 gr) were separated into 3 groups (10 mice per group): Group 1: control $\left(37^{\circ} \mathrm{C}\right)$-untreated, Group 2: hyperthermia $\left(43^{\circ} \mathrm{C}\right)$-treated and Group 3: hyperthermia $\left(45^{\circ} \mathrm{C}\right)$-treated. B16-F10 (melanoma) or CT26 (colon carcinoma) cells were plated in $100 \mathrm{~mm}^{3}$ dishes and on the following day were exposed to either $37^{\circ} \mathrm{C}, 43^{\circ} \mathrm{C}$ or $45^{\circ} \mathrm{C}$, for $1 \mathrm{~h}$. Then, the cells were returned to $37^{\circ} \mathrm{C}$ for a $24 \mathrm{~h}$ post-exposure incubation period. Cells were trypsinized and a cell suspension containing $0.5 \times 10^{6}$ cells in $150 \mu \mathrm{l}$ PBS was injected subcutaneously into the back of the neck of each mouse. B16-F10 and CT26 cells were utilized for inducing the melanoma and colon carcinoma tumors respectively. Tumors were grown for 12-14 days until they became visible. Then, the mice were sacrificed by cervical dislocation and the tumors were excised. Tumor volume and incidence were determined. Tumor dimensions were measured by 
an electronic caliper whereas tumor volume was calculated by using the modified ellipsoid formula (width ${ }^{2} \times$ length) $/ 2$. The weight of each mouse was monitored during the experiment as well as signs of disease and/or discomfort. All efforts were made to ameliorate suffering whereas two independent experiments were performed to confirm the results.

Immunohistochemistry. Tumors were fixed in $10 \%$ formalin, then dehydrated in graded concentrations of ethanol and xylol and finally embedded in paraffin. Serial sections ( $3 \mu \mathrm{m}$ thick) from the formalin-fixed paraffin-embedded tissue blocks were prepared and floated onto charged glass slides. A hematoxylin and eosin stained section was obtained from each tissue block. Immunostaining was performed on formalin-fixed, paraffin-embedded tissue sections by the streptavidin-biotin peroxidase labeled (LSAB) method. Sections were de-paraffinized after being washed 3 times ( 5 min each) in xylene. Afterwards, they were hydrated by using graded concentrations of ethanol to $\mathrm{dH}_{2} \mathrm{O}$. Tissue sections were subjected to antigen retrieval by heating in $1 \times$ citrate unmasking solution until boiling, followed by an additional incubation at a sub-boiling temperature $\left(95-98^{\circ} \mathrm{C}\right)$ for $10 \mathrm{~min}$. For blocking endogenous peroxidase activity, the slides were incubated with $3 \%(\mathrm{v} / \mathrm{v})$ hydrogen peroxide $(10 \mathrm{~min})$, washed twice with $\mathrm{dH}_{2} \mathrm{O}(5 \mathrm{~min})$ and once in TBST buffer (5 min). During the next step, the sections were incubated with blocking buffer ( $1 \mathrm{~h}$ at RT) followed by overnight incubation with primary antibody at $4^{\circ} \mathrm{C}$. The sections were washed with TBST buffer 3 times $(5 \mathrm{~min})$ after removing the primary antibody, covered with a few drops of SignalStain Boost Detection Reagent (HRP, rabbit) and then were further incubated in a humidified chamber (30 min at RT). Moreover, they were washed 3 times with TBST buffer (5 min each) before adding DAB chromogen solution onto each slide, incubated for further 1-10 min (while staining was monitored under a microscope), washed 3 times with TBST buffer (10 min each) and finally washed in $\mathrm{dH}_{2} \mathrm{O}$ Staining was followed by counterstaining with hematoxylin and eventually samples were mounted and covered with coverslips. An image analysis system composed of the Olympus BX43 upright microscope, digital camera Olympus Cam-SC30 and soft analysis (analySISH) was used for all tumor sections (stained with antibodies and counterstained with hematoxylin). Immunostaining was assessed by a developed continuous score system where the number of immunopositive cells was divided by the total number of the counted cells while the expression was defined as the percentage of positive cells of the total number of counted cells. All antibodies were obtained from Cell Signaling Technology (Danvers, MA, USA) and were utilized according to the manufacturer's instructions.

Data analysis. Data were expressed as mean values \pm SEM and comparisons were made between control and treatment groups. Calculations were performed by using the Microsoft Office Excel 2016 software. Means were compared by one-way analysis of variance (one-way ANOVA) with Tukey's test for multiple comparisons. SPSS v.22 or PRISM v5.01 software was used for statistical tests. A value of $p<0.05$ was considered statistically significant.

Ethics statement. All animal experiments were approved by the Animal Care and Use Committee of the Veterinary Department of Evros Prefecture (License No. EL1BIOexp1) and complied with the requirements set by Directive 86/609/EEC and PD160/91 (the legislation in force at the time of experimentation). All experiments were conducted considering the 3R's (Replacement, Refinement, Reduction) policy while all mice were not subjected to any painful or discomforting conditions.

\section{Results}

In the present study, we utilized two in vivo murine models of malignant melanoma and colon carcinoma in order to examine hyperthermia's therapeutic effectiveness. Firstly, we aimed to validate our previous in vitro findings showing hyperthermia's capacity to activate apoptotic cell death in human malignant melanoma (A375) cells (39). For this reason, an in vivo murine model of malignant melanoma was utilized by injecting B16-F10 cells into the subcutaneous tissue of the back of the neck of C57BL/6 female mice. Although we exposed B16-F10 cells to $43^{\circ} \mathrm{C}$ or $45^{\circ} \mathrm{C}$ for various incubation periods, $1 \mathrm{~h}$ of hyperthermic exposure was considered optimal as shorter or longer incubation periods caused either no significant or very extensive induction of cytotoxicity (data not shown). Consequently, $1 \mathrm{~h}$ of hyperthermic exposure led to significant drop in cell viability levels recorded $24 \mathrm{~h}$ post exposure (Figure 1A). For the induction of tumors, B16-F10 cells were exposed to $43^{\circ} \mathrm{C}$ and $45^{\circ} \mathrm{C}$ (treatment groups) or to $37^{\circ} \mathrm{C}$ (control group) for $1 \mathrm{~h}$, incubated for $24 \mathrm{~h}$ post-exposure and then injected subcutaneously in female C57BL/6 mice. Our results showed that there was a significant effect of hyperthermia in inhibiting tumor growth at $43^{\circ} \mathrm{C}$ which was even more profound at $45^{\circ} \mathrm{C}$. More specifically, the average tumor size dropped from about $3,000 \mathrm{~mm}^{3}\left(37^{\circ} \mathrm{C}\right)$ to $2,000 \mathrm{~mm}^{3}\left(43^{\circ} \mathrm{C}\right)$ to even lower than $1,000 \mathrm{~mm}^{3}\left(45^{\circ} \mathrm{C}\right)$ (Figures $\left.1 \mathrm{~B}-\mathrm{C}\right)$. In addition, changes in protein expression levels of different markers associated with the observed reduction in tumor size were examined by immunohistochemistry. To this end, increased levels of active caspase-3, reduced levels of COX-2 and increased levels of phospho-H2A.X (Ser139) were recorded in both hyperthermia-treated groups compared to the control group thus indicating the effectiveness of hyperthermia as a treatment modality (Figure 1D).

In addition, we utilized an in vivo model of colon carcinoma in order to demonstrate hyperthermia's therapeutic efficacy in a different type of cancer. For this reason, we have utilized the CT26 colon carcinoma cell line in which, once again, $1 \mathrm{~h}$ of exposure at $43^{\circ} \mathrm{C}$ or $45^{\circ} \mathrm{C}$ respectively had a similar effect on cell viability levels as the one observed with B16-F10 cells (Figure 2A). Similarly, CT-26 cells exposed to hyperthermic conditions, for $1 \mathrm{~h}$, were further incubated for $24 \mathrm{~h}$ post-exposure at $37^{\circ} \mathrm{C}$ and then injected subcutaneously in female BALB/c mice. Our data indicated that there was a considerable reduction in tumor size in both hyperthermia-treated groups compared to control. More 


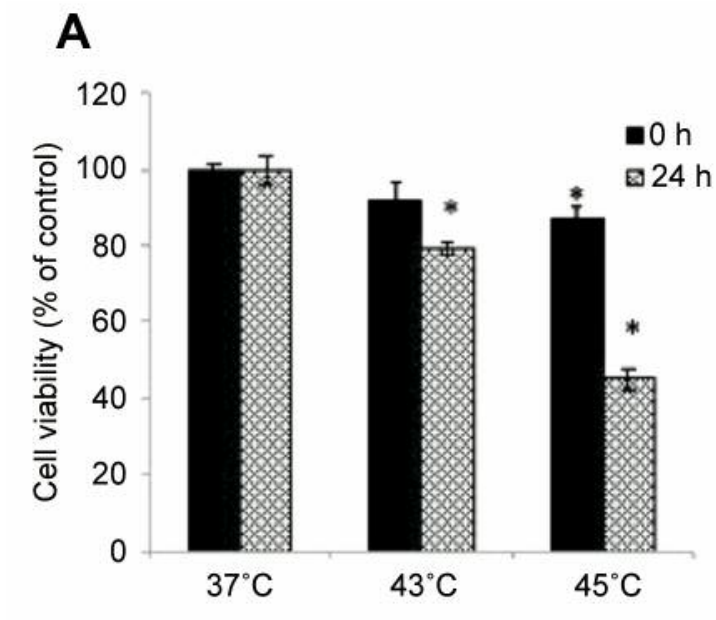

B
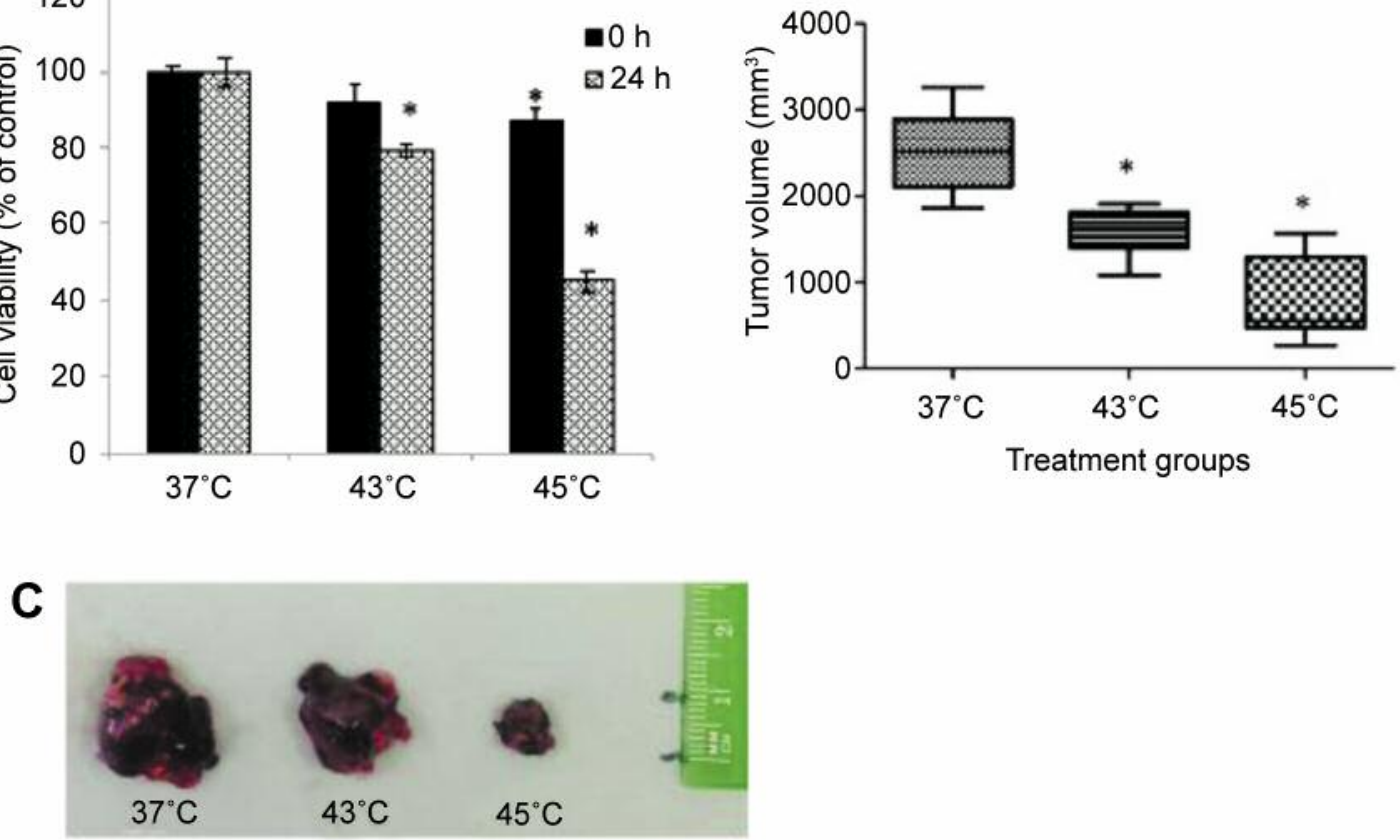

D

$37^{\circ} \mathrm{C}$

$43^{\circ} \mathrm{C}$

$45^{\circ} \mathrm{C}$

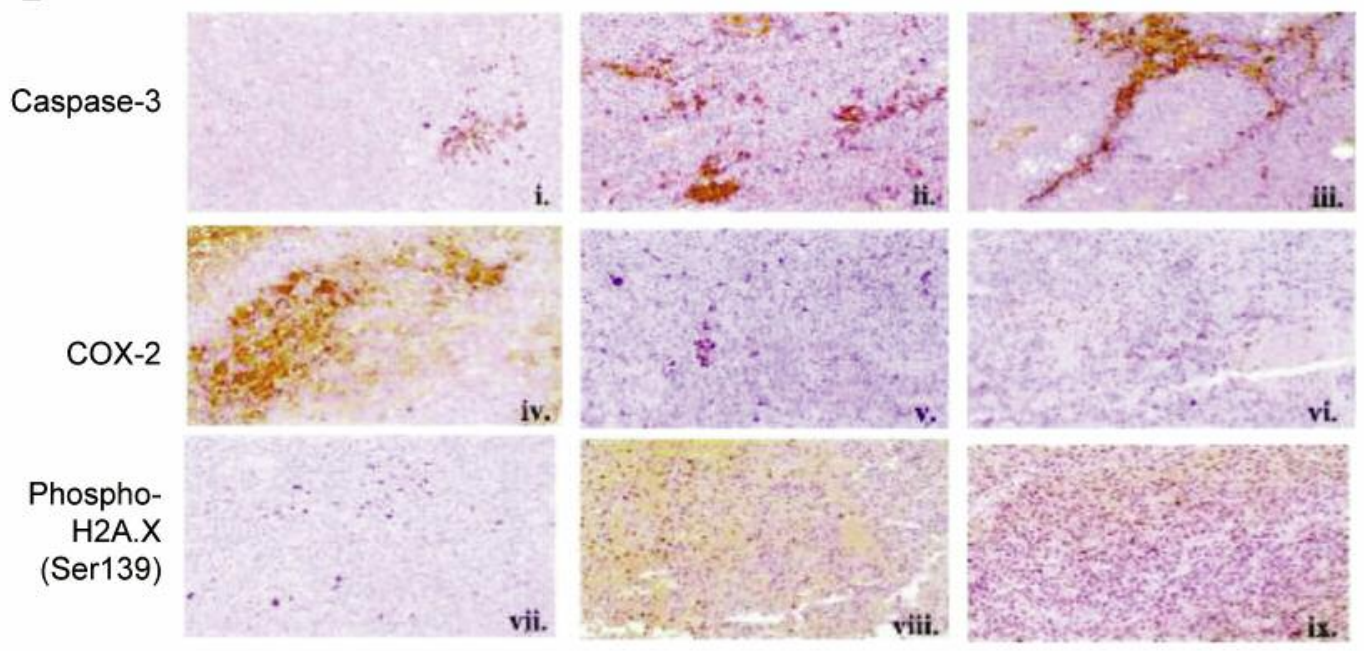

Figure 1. Therapeutic effectiveness of hyperthermia in an in vivo murine model of malignant melanoma. (A) Cell viability levels of B16-F10 cells immediately after and $24 \mathrm{~h}$ after exposures at 37,43 and $45^{\circ} \mathrm{C}$ for $1 \mathrm{~h}(N=5) ;(B)$ Average tumor volume growth $(N=10)(p<0.05) ;(C)$ representative tumors; (D) Immunohistological staining of caspase-3 (upper panel), COX-2 (middle panel) and phospho-H2A.X (Ser139) (lower panel); Asterisk (*) indicates statistical significance at $p<0.05$ for comparison with control at $37^{\circ} \mathrm{C}$.

specifically, average tumor size for the control group was about $2,000 \mathrm{~mm}^{3}$ in comparison to about $1,500 \mathrm{~mm}^{3}$ and lower than $1,000 \mathrm{~mm}^{3}$ in both hyperthermia-treated groups respectively (Figures $2 \mathrm{~B}$ and $\mathrm{C}$ ). In addition, cleaved caspase-3 protein levels demonstrated a considerable elevation in the tumors from the $43^{\circ} \mathrm{C}$ hyperthermia-treated group, compared to the control $\left(37^{\circ} \mathrm{C}\right)$ group, and even more so with the $45^{\circ} \mathrm{C}$ hyperthermia-treated group (Figure 2D). Furthermore, $\mathrm{COX}-2$ protein levels were found to be decreased while phospho-H2A.X (Ser139) increased in both 
A

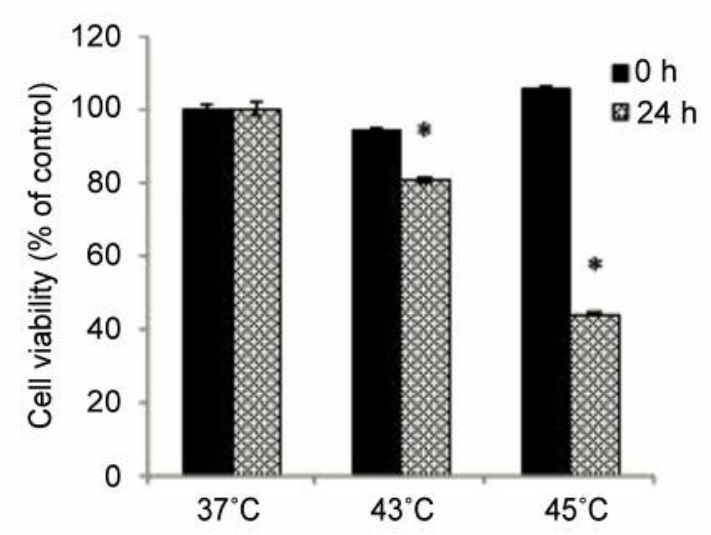

B

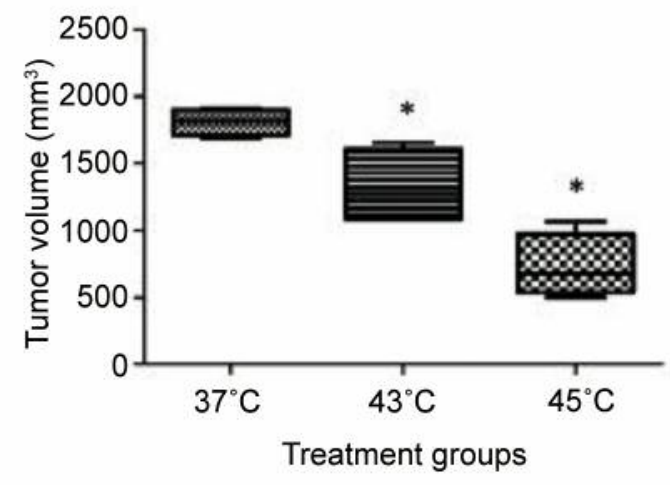

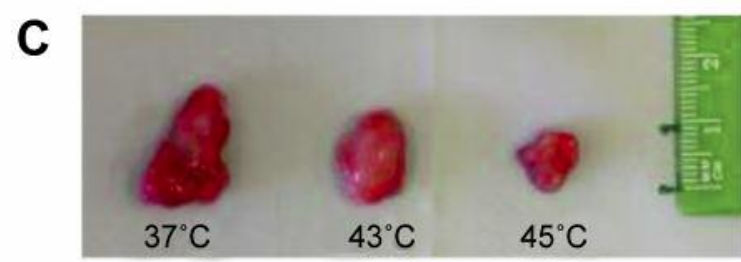
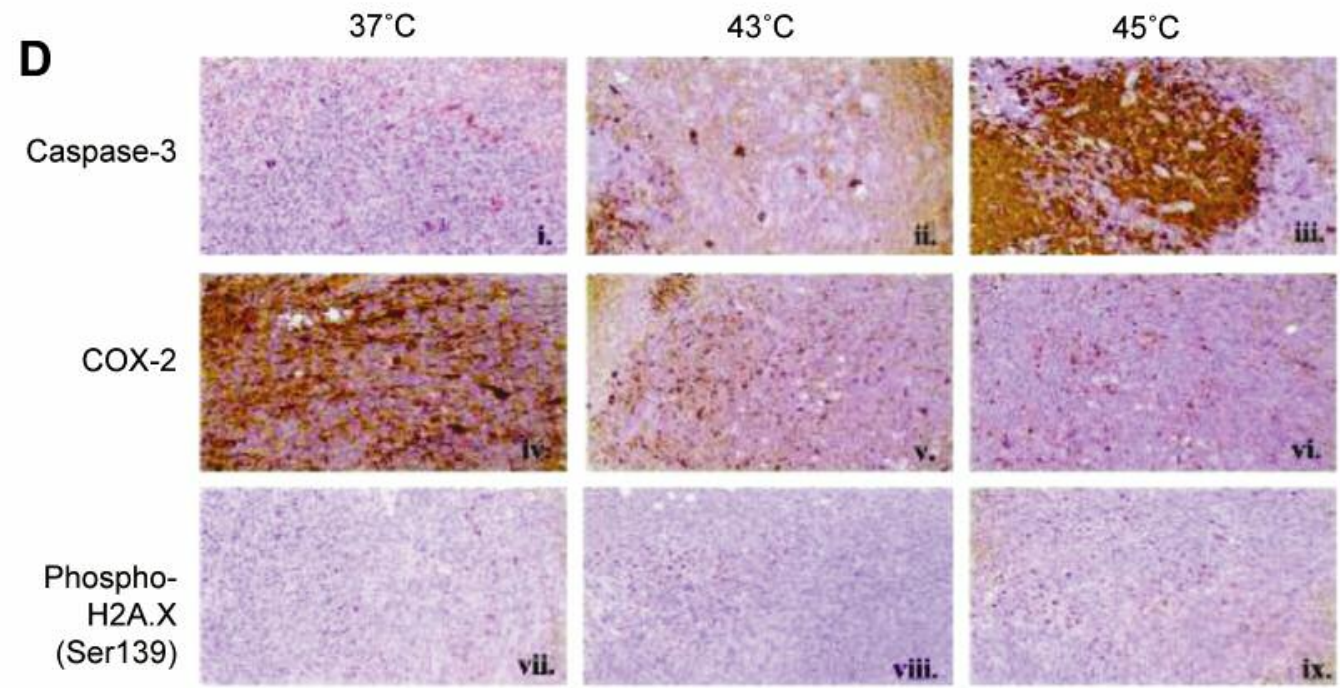

Figure 2. Therapeutic effectiveness of hyperthermia in an in vivo murine model of colon carcinoma. (A) Cell viability levels of CT26 cells immediately after and $24 \mathrm{~h}$ after exposure at 37,43 and $45^{\circ} \mathrm{C}$ for $1 \mathrm{~h}(N=5) ;(B)$ Average tumor volume growth $(N=5)(p<0.05)$; (C) representative tumors; $(D)$ Immunohistological staining of caspase-3 (upper panel), COX-2 (middle panel) and phospho-H2A.X (Ser139) (lower panel); Asterisk (*) indicates statistical significance at $p<0.05$ for comparison with control at $37^{\circ} \mathrm{C}$.

hyperthermia-treated groups when compared to the control group (Figure 2D).

Overall, our data document hyperthermia's potential to inhibit tumor growth in in vivo murine models of melanoma and colon carcinoma thus representing an alternative and efficient approach in the context of cancer therapeutics.

\section{Discussion}

Early studies have shown that hyperthermia in combination with radiation therapy can exert beneficial effects in treating tumor cells (30). Various studies utilizing different cancer cell lines and models have looked into the role of apoptosis as a 
consequence of heat application. According to their findings, the induction of cell death pathways is dependent on i) cancer cell type, ii) temperature and iii) duration of heat exposure (40, 41). Previously we demonstrated that hyperthermia induces various apoptotic cascades and enhances the therapeutic effectiveness of non-targeted and targeted drugs in an in vitro model of human malignant melanoma (39). To this end, the aim of this study was to validate our previous in vitro findings in two in vivo models of murine malignant melanoma and colon carcinoma in an attempt to demonstrate hyperthermia's effectiveness as a cancer treatment option.

Overall, we have shown that exposure to hyperthermic conditions increased cytotoxicity in both melanoma (B16-F10) and colon carcinoma (CT26) cells. Our in vitro findings are aligned with those of several studies examining hyperthermia's effectiveness on proliferation and therapeutic potential in these cell lines $(33,42-45)$. Furthermore, we have shown a remarkably prominent inhibition of tumor volume and size between hyperthermic and control conditions which further supports the significance of hyperthermia's therapeutic potential. A large number of studies are also in agreement with our in vivo findings although their focus was primarily on determining the efficacy of various clinical therapeutic protocols in combination with hyperthermia (43-52).

A prominent finding in our study was the activation of the apoptotic pathway as evidenced by an increased expression of cleaved caspase- 3 in both hyperthermia-treated groups. These results are in accordance with our previous in vitro findings together with observations, by other groups, showing the involvement of caspase- 3 in triggering the apoptotic response in a number of different therapeutic protocols combined with hyperthermia $(45,46,48,51)$. In contrast, COX-2 was shown to be expressed in significantly lower levels in the tumors of both hyperthermia-treated groups, a finding also in agreement with earlier studies exhibiting an increased expression of COX-2 in metastatic melanoma lesions and cell lines while being undetected in lesions of primary stages (53). Consequently, COX-2 levels are utilized as a prognostic marker for melanoma development $(54,55)$. Furthermore, results from a recent study have shown an increased expression of COX-2 in clinical samples, from patients with cutaneous melanoma, to be associated with poor prognosis and a high metastatic risk (56). Similarly, there is clear evidence for the role of elevated COX-2 expression levels concomitant with an increased metastatic potential and poor prognosis in colorectal carcinoma $(57,58)$. Therefore, the remarkable hyperthermia-induced reduction in the expression levels of COX-2, in both experimental models, further strengthens the evidence for its role as a promising therapeutic strategy. Last but not least, our data indicated that there was a considerable hyperthermia-induced increase in the protein content of phospho-H2A.X (Ser139) in tumors from both experimental models suggestive of a temperature-dependent elevation in double-stranded DNA breaks as a response to hyperthermia. Previous studies have demonstrated that exposing cells to $>40^{\circ} \mathrm{C}$ triggers the generation of double-stranded DNA breaks which, in turn, can induce cell death (59-61) and/or interfere with DNA repair mechanisms (62-64). Furthermore, results from another study revealed elevated phospho-H2A.X levels in clinical samples from colon carcinoma patients to be associated with poor prognosis of the disease (65). These findings illustrate the significance of implementing hyperthermia as a means of targeting the DNA of tumor cells and thus exert its therapeutic potency.

Overall, our study demonstrated that exposure to hyperthermia was associated with reduced post-in vitro proliferation, reduction of tumor cell growth, as well as activation of apoptotic cell death and induction of DNA damage in both in vivo models of malignant melanoma and colon carcinoma. Collectively, our data demonstrate the capacity of hyperthermia to exert its therapeutic benefits (against different types of cancers) by affecting a range of critical cellular cascades. However, although our findings support the significance of implementing hyperthermia as a therapeutic strategy, further exploitation is necessary in order to identify the molecular underlying mechanisms by which heat elevation exerts its cancer therapeutic effectiveness.

\section{Authors' Contributions}

MIP initiated and designed the study. TM, SB, SP, CS, KC, AP codesigned the study. EL performed the immunohistochemistry work. SV performed the animal experiments. TM, SV, EL, SB, SP, CS, $\mathrm{KC}, \mathrm{AP}$ and MIP evaluated, analysed and interpreted the data. TM and MIP wrote the manuscript. SV, EL, SB, SP, CS, KC and AP revised the manuscript.

\section{Conflicts of Interest}

None to declare.

\section{Acknowledgements}

This work was supported, in part, by i) HWU and UNN start-up funds (MIP) including a HWU PhD studentship (TM) and ii) cofinanced by EU [European Regional Development Fund-ERDF] and Greek national funds [through the Operational Program National Action "Cooperation 2011-Partnerships of Production \& Research Institutions in Focused Research \& Technology Sectors"; Project Nr. 11SYN_2_566] (AP \& KC).

\section{References}

1 Apalla Z, Nashan D, Weller RB and Castellsague X: Skin cancer: Epidemiology, disease burden, pathophysiology, diagnosis, and therapeutic approaches. Dermatol Ther (Heidelb) 7(Suppl 1): 519, 2017. PMID: 28150105. DOI: 10.1007/ s13555-016-0165-y 
2 Apalla Z, Lallas A, Sotiriou E, Lazaridou E and Ioannides D: Epidemiological trends in skin cancer. Dermatol Pract Concept 7(2): 1-6, 2017. PMID: 28515985. DOI: 10.5826/dpc.0702a01

3 Arnold M, Holterhues C, Hollestein LM, Coebergh JW, Nijsten T, Pukkala E, Holleczek B, Tryggvadottir L, Comber H, Bento MJ, Diba ChS, Micallef R, Primic-Zakelj M, Izarzugaza MI, Perucha J, Marcos-Gragera R, Galceran J, Ardanaz E, Schaffar R, Pring A and de Vries E: Trends in incidence and predictions of cutaneous melanoma across europe up to 2015. J Eur Acad Dermatol Venereol 28(9): 1170-1178, 2014. PMID: 23962170. DOI: $10.1111 /$ jdv.12236

4 Matthews NH, Li WQ, Qureshi AA, Weinstock MA and Cho E: Epidemiology of melanoma. In: Cutaneous melanoma: Etiology and therapy. Ward WH and Farma JM (eds.). Codon Publications The Authors: Brisbane (AU), 2017.

5 Erb P, Ji J, Kump E, Mielgo A and Wernli M: Apoptosis and pathogenesis of melanoma and nonmelanoma skin cancer. Adv Exp Med Biol 624: 283-295, 2008. PMID: 18348464. DOI: 10.1007/978-0-387-77574-6_22

6 Regad T: Molecular and cellular pathogenesis of melanoma initiation and progression. Cell Mol Life Sci 70(21): 4055-4065, 2013. PMID: 23532409. DOI: 10.1007/s00018-013-1324-2

7 Russak JE and Rigel DS: Risk factors for the development of primary cutaneous melanoma. Dermatol Clin 30(3): 363-368, 2012. PMID: 22800544. DOI: 10.1016/j.det.2012.05.002

8 Runger TM: Mechanisms of melanoma promotion by ultraviolet radiation. J Invest Dermatol 136(9): 1751-1752, 2016. PMID: 27542295. DOI: $10.1016 /$ j.jid.2016.04.001

9 Kanavy HE and Gerstenblith MR: Ultraviolet radiation and melanoma. Semin Cutan Med Surg 30(4): 222-228, 2011. PMID: 22123420. DOI: 10.1016/j.sder.2011.08.003

10 Sample A and He YY: Mechanisms and prevention of uvinduced melanoma. Photodermatol Photoimmunol Photomed 34(1): 13-24, 2018. PMID: 28703311. DOI: 10.1111/phpp.12329

11 Liu Y and Sheikh MS: Melanoma: Molecular pathogenesis and therapeutic management. Mol Cell Pharmacol 6(3): 228, 2014. PMID: 25745537.

12 Gaudi S and Messina JL: Molecular bases of cutaneous and uveal melanomas. Patholog Res Int 2011: 159421, 2011. PMID: 21876842. DOI: $10.4061 / 2011 / 159421$

13 Leonardi GC, Falzone L, Salemi R, Zanghi A, Spandidos DA, McCubrey JA, Candido S and Libra M: Cutaneous melanoma: From pathogenesis to therapy (review). Int J Oncol 52(4): 10711080, 2018. PMID: 29532857. DOI: 10.3892/ijo.2018.4287

14 Rozeman EA, Dekker TJA, Haanen J and Blank CU: Advanced melanoma: Current treatment options, biomarkers, and future perspectives. Am J Clin Dermatol 19(3): 303-317, 2018. PMID: 29164492. DOI: 10.1007/s40257-017-0325-6

15 Domingues B, Lopes JM, Soares P and Populo H: Melanoma treatment in review. Immunotargets Ther 7: 35-49, 2018. PMID: 29922629. DOI: 10.2147/ITT.S134842

16 Ewing I, Hurley JJ, Josephides E and Millar A: The molecular genetics of colorectal cancer. Frontline Gastroenterol 5(1): 26-30, 2014. PMID: 24416503. DOI: 10.1136/flgastro-2013100329

17 Fleming M, Ravula S, Tatishchev SF and Wang HL: Colorectal carcinoma: Pathologic aspects. J Gastrointest Oncol 3(3): 153-173, 2012. PMID: 22943008. DOI: 10.3978/j.issn.2078-6891.2012.030

18 Arnold M, Sierra MS, Laversanne M, Soerjomataram I, Jemal A and Bray F: Global patterns and trends in colorectal cancer incidence and mortality. Gut 66(4): 683-691, 2017. PMID: 26818619. DOI: 10.1136/gutjnl-2015-310912

19 Araghi M, Soerjomataram I, Jenkins M, Brierley J, Morris E, Bray $\mathrm{F}$ and Arnold M: Global trends in colorectal cancer mortality: Projections to the year 2035. Int J Cancer, 2018. PMID: 30536395. DOI: 10.1002/ijc.32055

20 De Rosa M, Pace U, Rega D, Costabile V, Duraturo F, Izzo P and Delrio P: Genetics, diagnosis and management of colorectal cancer (review). Oncol Rep 34(3): 1087-1096, 2015. PMID: 26151224. DOI: $10.3892 /$ or.2015.4108

21 Burt RW: Colon cancer screening. Gastroenterology 119(3): 837853, 2000. PMID: 10982778 .

22 Ma H, Brosens LAA, Offerhaus GJA, Giardiello FM, de Leng WWJ and Montgomery EA: Pathology and genetics of hereditary colorectal cancer. Pathology 50(1): 49-59, 2018. PMID: 29169633. DOI: 10.1016/j.pathol.2017.09.004

23 Markowitz SD and Bertagnolli MM: Molecular origins of cancer: Molecular basis of colorectal cancer. N Engl J Med 361(25): 24492460, 2009. PMID: 20018966. DOI: 10.1056/NEJMra0804588

24 Kanthan R, Senger JL and Kanthan SC: Molecular events in primary and metastatic colorectal carcinoma: A review. Patholog Res Int 2012: 597497, 2012. PMID: 22997602. DOI: 10.1155/ 2012/597497

25 Martini G, Troiani T, Cardone C, Vitiello P, Sforza V, Ciardiello D, Napolitano S, Della Corte CM, Morgillo F, Raucci A, Cuomo A, Selvaggi F, Ciardiello F and Martinelli E: Present and future of metastatic colorectal cancer treatment: A review of new candidate targets. World J Gastroenterol 23(26): 4675-4688, 2017. PMID: 28765689. DOI: 10.3748/wjg.v23.i26.4675

26 Kuipers EJ, Grady WM, Lieberman D, Seufferlein T, Sung JJ, Boelens PG, van de Velde CJ and Watanabe T: Colorectal cancer. Nat Rev Dis Primers 1: 15065, 2015. PMID: 27189416. DOI: $10.1038 / \mathrm{nrdp} .2015 .65$

27 Wrobel P and Ahmed S: Current status of immunotherapy in metastatic colorectal cancer. Int J Colorectal Dis 34(1): 13-25, 2019. PMID: 30465238. DOI: 10.1007/s00384-018-3202-8

28 Bettaieb A, Wrzal PK and Averill-Bates DA: Hyperthermia: Cancer treatment and beyond. In: Cancer treatment conventional and innovative approaches. Rangel L (ed.). InTech: Rijeka, pp. 258-283, 2013.

29 Robinson JE, Wizenberg MJ and McCready WA: Combined hyperthermia and radiation suggest and alternative to heavy particle therapy for reduced oxygen enhancement ratios. Nature 251(5475): 521-522, 1974. PMID: 4214001.

30 Gerner EW, Connor WG, Boone ML, Doss JD, Mayer EG and Miller RC: The potential of localized heating as a adjunct to radiation therapy. Radiology 116(2): 433-439, 1975. PMID: 1098102. DOI: $10.1148 / 116.2 .433$

31 Ito A, Tanaka K, Honda H, Abe S, Yamaguchi H and Kobayashi T: Complete regression of mouse mammary carcinoma with a size greater than $15 \mathrm{~mm}$ by frequent repeated hyperthermia using magnetite nanoparticles. J Biosci Bioeng 96(4): 364-369, 2003. PMID: 16233538. DOI: 10.1016/S1389-1723(03)90138-1

32 Ito A, Tanaka K, Kondo K, Shinkai M, Honda H, Matsumoto K, Saida $\mathrm{T}$ and Kobayashi $\mathrm{T}$ : Tumor regression by combined immunotherapy and hyperthermia using magnetic nanoparticles in an experimental subcutaneous murine melanoma. Cancer Sci 94(3): 308-313, 2003. PMID: 12824927.

33 Garcia MP, Cavalheiro JR and Fernandes MH: Acute and longterm effects of hyperthermia in b16-f10 melanoma cells. PLoS 
One 7(4): e35489, 2012. PMID: 22532856. DOI: 10.1371/ journal.pone.0035489

34 Zhang JF, Yan XM, Lan B, Lei YR, Li XH, Gao S, Guo YF and Guo F: Molecular mechanisms of synergistic induction of apoptosis by the combination therapy with hyperthermia and cisplatin in prostate cancer cells. Biochem Biophys Res Commun 479(2): 159-165, 2016. PMID: 27524236. DOI: 10.1016/j.bbrc.2016.08.060

35 Hou CH, Lin FL, Hou SM and Liu JF: Hyperthermia induces apoptosis through endoplasmic reticulum and reactive oxygen species in human osteosarcoma cells. Int J Mol Sci 15(10): 1738017395, 2014. PMID: 25268613. DOI: 10.3390/ijms 151017380

36 Hildebrandt B, Wust P, Ahlers O, Dieing A, Sreenivasa G, Kerner T, Felix R and Riess H: The cellular and molecular basis of hyperthermia. Crit Rev Oncol Hematol 43(1): 33-56, 2002. PMID: 12098606.

37 Dewhirst MW, Vujaskovic Z, Jones E and Thrall D: Re-setting the biologic rationale for thermal therapy. Int J Hyperthermia 21(8): 779-790, 2005. PMID: 16338861. DOI: 10.1080/02 656730500271668

38 Dewhirst MW, Lee CT and Ashcraft KA: The future of biology in driving the field of hyperthermia. Int J Hyperthermia 32(1): 4-13, 2016. PMID: 26850697. DOI: 10.3109/02656736.2015. 1091093

39 Mantso T, Vasileiadis S, Anestopoulos I, Voulgaridou GP, Lampri E, Botaitis S, Kontomanolis EN, Simopoulos C, Goussetis G, Franco R, Chlichlia K, Pappa A and Panayiotidis MI: Hyperthermia induces therapeutic effectiveness and potentiates adjuvant therapy with non-targeted and targeted drugs in an in vitro model of human malignant melanoma. Sci Rep 8(1): 10724, 2018. PMID: 30013176. DOI: 10.1038/s41598018-29018-0

40 Dieing A, Ahlers O, Hildebrandt B, Kerner T, Tamm I, Possinger $\mathrm{K}$ and Wust P: The effect of induced hyperthermia on the immune system. Prog Brain Res 162: 137-152, 2007. PMID: 17645918. DOI: 10.1016/S0079-6123(06)62008-6

41 Wrzal PK, Bettaieb A and Averill-Bates DA: Molecular mechanisms of apoptosis activation by heat shock in multidrugresistant chinese hamster cells. Radiat Res 170(4): 498-511, 2008. PMID: 19024657.

42 Jin H, Xie X, Hu B, Gao F, Zhou J, Zhang Y, Du L, Wang X, Zhao L, Zhang X, Shen L, Liao Y and Tang J: Hyperthermia inhibits the proliferation and invasive ability of mouse malignant melanoma through tgf-beta(1). Oncol Rep 29(2): 725-734, 2013. PMID: 23135570. DOI: 10.3892/or.2012.2128

43 Costa Lima SA, Gaspar A, Reis S and Duraes L: Multifunctional nanospheres for co-delivery of methotrexate and mild hyperthermia to colon cancer cells. Mater Sci Eng C Mater Biol Appl 75: 1420-1426, 2017. PMID: 28415433. DOI: 10.1016/ j.msec.2017.03.049.

44 Lim SK, Shin DH, Choi MH and Kim JS: Enhanced antitumor efficacy of gemcitabine-loaded temperature-sensitive liposome by hyperthermia in tumor-bearing mice. Drug Dev Ind Pharm 40(4): 470-476, 2014. PMID: 26090123.

45 Nie W, Ma XL, Sang YX, Li YL, Gao X, Xu GC, Shen GB, Shi HS, Liu XX, Wang FT and Wei YQ: Synergic antitumor effect of sklb1002 and local hyperthermia in 4t1 and ct26. Clin Exp Med 14(2): 203-213, 2014. PMID: 23263406. DOI: 10.1007/ s10238-012-0225-2

46 Portela A, Vasconcelos M, Fernandes MH, Garcia M, Silva A, Gabriel J, Gartner F, Amorim I and Cavalheiro J: Highly focalised thermotherapy using a ferrimagnetic cement in the treatment of a melanoma mouse model by low temperature hyperthermia. Int J Hyperthermia 29(2): 121-132, 2013. PMID: 23418916. DOI: 10.3109/02656736.2013.767478

47 Kim YS, Lee TH and O'Neill BE: Non-lethal heat treatment of cells results in reduction of tumor initiation and metastatic potential. Biochem Biophys Res Commun 464(1): 51-56, 2015. PMID: 26032500. DOI: 10.1016/j.bbrc.2015.05.093

48 Haghniaz R, Umrani RD and Paknikar KM: Hyperthermia mediated by dextran-coated la $0.7 \mathrm{sr} 0.3 \mathrm{mno} 3$ nanoparticles: In vivo studies. Int J Nanomedicine 11: 1779-1791, 2016. PMID: 27175076. DOI: $10.2147 / \mathrm{IJN}$.S 104617

49 Misir Krpan A, Ivankovic S, Krajina Z, Ivankovic D and Stojkovic R: Tamoxifen in trimodal therapy with cytotoxic drugs and hyperthermia in vivo significantly enhance therapeutic efficacy against b16-f10 melanoma. Tumori 98(2): 257-263, 2012. PMID: 25535979. DOI: 10.1097/CAD.0000000000000197

50 Werthmoller N, Frey B, Ruckert M, Lotter M, Fietkau R and Gaipl US: Combination of ionising radiation with hyperthermia increases the immunogenic potential of b16-f10 melanoma cells in vitro and in vivo. Int J Hyperthermia 32(1): 23-30, 2016. PMID: 26754406. DOI: 10.3109/02656736.2015. 1106011

51 Tsang YW, Huang CC, Yang KL, Chi MS, Chiang HC, Wang YS, Andocs G, Szasz A, Li WT and Chi KH: Improving immunological tumor microenvironment using electrohyperthermia followed by dendritic cell immunotherapy. BMC Cancer 15: 708, 2015. PMID: 26472466. DOI: 10.1186/s12885015-1690-2

52 Li ZM, Zhao YW, Zhao CJ, Zhang XP, Chen LJ, Wei YQ and Yang HS: Hyperthermia increases the therapeutic efficacy of survivint34a in mouse tumor models. Cancer Biol Ther 12(6): 523-530, 2011. PMID: 21743297.

53 Goulet AC, Einsphar JG, Alberts DS, Beas A, Burk C, Bhattacharyya A, Bangert J, Harmon JM, Fujiwara H, Koki A and Nelson MA: Analysis of cyclooxygenase 2 (cox-2) expression during malignant melanoma progression. Cancer Biol Ther 2(6): 713-718, 2003. PMID: 14688483.

54 Becker MR, Siegelin MD, Rompel R, Enk AH and Gaiser T: Cox-2 expression in malignant melanoma: A novel prognostic marker? Melanoma Res 19(1): 8-16, 2009. PMID: 19430402. DOI: $10.1097 / C M R .0 b 013 \mathrm{e} 32831 \mathrm{~d} 7 \mathrm{f5} 2$

55 Meyer S, Vogt T, Landthaler M, Berand A, Reichle A, Bataille F, Marx AH, Menz A, Hartmann A, Kunz-Schughart LA and Wild PJ: Cyclooxygenase $2(\operatorname{cox} 2)$ and peroxisome proliferatoractivated receptor gamma (pparg) are stage-dependent prognostic markers of malignant melanoma. PPAR Res 2009: 848645, 2009. PMID: 19639032. DOI: 10.1155/2010/848645

56 Kuzbicki L, Lange D, Stanek-Widera A and Chwirot BW: Intratumoral expression of cyclooxygenase-2 (cox-2) is a negative prognostic marker for patients with cutaneous melanoma. Melanoma Res 26(5): 448-456, 2016. PMID: 29707138. DOI: 10.18632 /oncotarget. 24825

57 Rahman M, Selvarajan K, Hasan MR, Chan AP, Jin C, Kim J, Chan SK, Le ND, Kim YB and Tai IT: Inhibition of cox-2 in colon cancer modulates tumor growth and mdr-1 expression to enhance tumor regression in therapy-refractory cancers in vivo. Neoplasia 14(7): 624-633, 2012. PMID: 22904679.

58 Wang D and Dubois RN: The role of cox-2 in intestinal inflammation and colorectal cancer. Oncogene 29(6): 781-788, 2010. PMID: 19946329. DOI: 10.1038/onc.2009.421 
59 Takahashi A, Matsumoto H, Nagayama K, Kitano M, Hirose S, Tanaka H, Mori E, Yamakawa N, Yasumoto J, Yuki K, Ohnishi $\mathrm{K}$ and Ohnishi T: Evidence for the involvement of double-strand breaks in heat-induced cell killing. Cancer Res 64(24): 88398845, 2004. PMID: 15604242. DOI: 10.1158/0008-5472-CAN04-1876

60 Takahashi A, Mori E, Somakos GI, Ohnishi K and Ohnishi T: Heat induces gammah2ax foci formation in mammalian cells Mutat Res 656(1-2): 88-92, 2008. PMID: 18765297. DOI: 10.1016/j.mrgentox.2008.07.012

61 El-Awady RA, Dikomey E and Dahm-Daphi J: Heat effects on dna repair after ionising radiation: Hyperthermia commonly increases the number of non-repaired double-strand breaks and structural rearrangements. Nucleic Acids Res 29(9): 1960-1966, 2001. PMID: 11328850.

62 Hunt CR, Pandita RK, Laszlo A, Higashikubo R, Agarwal M, Kitamura T, Gupta A, Rief N, Horikoshi N, Baskaran R, Lee JH, Lobrich M, Paull TT, Roti Roti JL and Pandita TK: Hyperthermia activates a subset of ataxia-telangiectasia mutated effectors independent of dna strand breaks and heat shock protein 70 status. Cancer Res 67(7): 3010-3017, 2007. PMID: 17409407. DOI: $10.1158 / 0008-5472 . C A N-06-4328$
63 Furusawa Y, Iizumi T, Fujiwara Y, Zhao QL, Tabuchi Y, Nomura $\mathrm{T}$ and Kondo $\mathrm{T}$ : Inhibition of checkpoint kinase 1 abrogates $\mathrm{g} 2 / \mathrm{m}$ checkpoint activation and promotes apoptosis under heat stress. Apoptosis 17(1): 102-112, 2012. PMID: 22080164. DOI: 10.1007/s 10495-011-0660-7

64 Schaaf L, Schwab M, Ulmer C, Heine S, Murdter TE, Schmid JO, Sauer G, Aulitzky WE and van der Kuip H: Hyperthermia synergizes with chemotherapy by inhibiting parp1-dependent dna replication arrest. Cancer Res 76(10): 2868-2875, 2016. PMID: 27013194. DOI: 10.1158/0008-5472.CAN-15-2908

65 Lee YC, Yin TC, Chen YT, Chai CY, Wang JY, Liu MC, Lin YC and Kan JY: High expression of phospho-h2ax predicts a poor prognosis in colorectal cancer. Anticancer Res 35(4): 2447-2453, 2015. PMID: 25862913.
Received April 1, 2019

Revised April 17, 2019

Accepted April 18, 2019 